\title{
ANALISIS KEPUASAN PASIEN RAWAT INAP PESERTA JAMINAN KESEHATAN NASIONAL DI RUMAH SAKIT ISLAM SITI KHADIJAH PALEMBANG
}

\author{
Nanda Arnindiah ${ }^{1}$, Dian Safriantini ${ }^{2 *}$ \\ ${ }^{1}$ Fakultas Kesehatan Masyarakat Universitas Sriwijaya J1. Palembang Prabumulih KM. \\ 32, Indralaya Indah Kabupaten Ogan Ilir, Sumatera Selatan. \\ Email: ${ }^{1}$ nandaarnindiah@gmail.com \\ ${ }^{2}$ Bagian Administrasi Kebijakan Kesehatan Fakultas Kesehatan Masyarakat Universitas \\ Sriwijaya. Jl. Palembang Prabumulih KM. 32, Indralaya Indah Kabupaten Ogan Ilir, \\ Sumatera. Email: 2dian.safriantini@gmail.com
}

\begin{abstract}
Abstrak
Indikator keberhasilan Jaminan Kesehatan Nasional adalah kepuasan masyarakat yang dinilai dari pelayanan rumah sakit, tetapi beberapa tahun terakhir kepuasan peserta cenderung rendah. Studi Pendahuluan di Rumah Sakit Islam Siti Khadijah Palembang menyatakan bahwa pasien peserta Jaminan Kesehatan Nasional merasa belum puas terhadap pelayanan yang diberikan. Oleh karena itu penelitian ini bertujuan untuk mengetahui tingkat kepuasan pasien rawat inap peserta Jaminan Kesehatan Nasional berdasarkan 5 dimensi kualitas pelayanan kesehatan. Jenis penelitian ini adalah analitik kuantitatif dengan rancangan cross sectional. Sampel penelitian berjumlah 73 pasien peserta Jaminan Kesehatan Nasional yang dipilih dengan metode proportional sampling. Dianalisis menggunakan Chi Square. Hasil penelitian menunjukkan bahwa rata-rata pasien peserta Jaminan Kesehatan Nasional $(54,8 \%)$ merasakan puas dengan pelayanan yang diberikan. Sedangkan hasil uji Chi Square menunjukkan nilai p value antara tangible $(0,003)$, reliability $(0,000)$, responsiveness $(0,000)$, assurance (0,000), empathy (0,000), dimana terdapat hubungan yang signifikan antara kelima dimensi mutu dengan kepuasan pasien. Dari komponen pada kelima dimensi mutu terdapat beberapa hal yang masih belum berjalan maksimal diantaranya adalah fasilitas yang belum maksimal seperti WC, estimasi waktu tunggu yang belum konsisten, komunikasi mengenai informasi kesehatan antara petugas kesehatan dan pasien yang belum baik, dan kurangnya waktu untuk berkonsultasi dengan dokter. Untuk mempertahankan kualitas pelayanan diharapkan Rumah Sakit Islam Siti Khadijah Palembang dapat melakukan perbaikan, peningkatan dan pengembangan sarana fisik. Bagi tenaga medis dan non-medis untuk lebih meningkatkan kualitas pelayanan baik dari segi kehandalan (reliability), ketanggapan (responsiveness), jaminan (assurance) dan perhatian (empathy).
\end{abstract}

Kata kunci: Kepuasan, kualitas pelayanan, peserta JKN, rumah sakit 


\begin{abstract}
The indicator of the success of the National Health Insurance is the satisfaction of the community assessed from hospital services, but in recent years participants' satisfaction has tended to be low. The Preliminary Study at the Siti Khadijah Islamic Hospital in Palembang stated that patients participating in the National Health Insurance felt dissatisfied with the services provided. Therefore this study aims to determine the level of satisfaction of inpatients of participants of the National Health Insurance based on 5 dimensions of quality of health services. This type of research is quantitative analytical with cross sectional design. The study sample consisted of 73 patients participating in the National Health Insurance selected by proportional sampling method. Analyzed using Chi Square. The results showed that on average patients participating in the National Health Insurance $(54.8 \%)$ felt satisfied with the services provided. While the Chi Square test results show the $\mathrm{p}$ value between tangible (0.003), reliability $(0,000)$, responsiveness $(0,000)$, assurance $(0,000)$, empathy $(0,000)$, where there is a significant relationship between the five quality dimensions and patient satisfaction. Of the components in the five dimensions of quality there are some things that are still not running optimally, among others are facilities that have not been maximized such as toilets, inconsistent waiting time estimates, communication about health information between health workers and patients who are not good, and lack of time to consult a doctor . To maintain the quality of service, it is expected that the Siti Khadijah Islamic Hospital in Palembang can improve, improve and develop physical facilities. For medical and non-medical personnel to further improve the quality of service both in terms of reliability, responsiveness, assurance and empathy.
\end{abstract}

Keywords: Satisfaction, quality, JKN participants, hospitals

\section{PENDAHULUAN}

WHO telah menyatakan bahwa
Universal Health Coverage (UHC)
merupakan isu terpenting bagi negara
maju dan negara berkembang dalam
bidang kesehatan. Pemerintah pusat
berkomitmen untuk mencapai Universal
Health Coverage (UHC) pada tahun 2019
sebagaimana diproyeksikan dalam Road
Map Jaminan Kesehatan Nasional (JKN),
atau Program Asuransi Kesehatan
Nasional, 2012-2019 (Ikegami, 2014).
Menurut GTZ.AUSAID (2012) dalam
Yandrizal dkk. (2015) menyatakan bahwa
Program Jaminan Kesehatan Nasional

(JKN) memberikan hak yang sama untuk semua peserta baik dalam akses sumber daya dibidang kesehatan dan memperoleh pelayanan kesehatan yang aman, bermutu, dan terjangkau sehingga menjamin kesejahteraan warga Negara Indonesia agar mereka dapat berproduktivitas dengan baik dan tidak berpikir dirinya miskin ketika jatuh sakit.

Di Kota Palembang sendiri kepesertaan BPJS Kesehatan yang tercatat sebanyak 2,47 juta jiwa atau $60 \%$ dari penduduk di Kota Palembang, sedangkan target yang harus dicapai sebanyak 2,87 juta jiwa atau $70 \%$ dari penduduk di Kota Palembang. Hal ini terlihat bahwa upaya 
yang dilakukan BPJS Kesehatan seoptimal mungkin untuk melaksanakan peran pentingnya bagi kesejahteraan penduduk. Selain kepesertaan tercatat juga fasilitas kesehatan yang bermitra dengan BPJS Kesehatan yaitu sebanyak 385 Fasilitas Kesehatan Tingkat Pertama (FKTP) meliputi 152 Puskesmas, 97 Dokter Perorangan, 15 Dokter Gigi Praktik Perorangan, dan 104 Klinik Utama. Sedangkan untuk Fasilitas Kesehatan Rujukan Tingkat Lanjutan (FKTRL) terdiri atas 34 Rumah Sakit, 10 Apotek, dan 12 Optik (BPJS Kesehatan, 2018).

Berdasarkan data Indeks Kepuasan Masyarakat di Rumah Sakit Islam Siti Khadijah Palembang yang diambil dalam penelitian Samsam Usama tentang "Analisa Kualitas Pelayanan Instalasi Rawat Jalan di Rumah Sakit Siti Khadijah Palembang Menggunakan Metode Servqual" menyimpulkan bahwa kualitas jasa pelayanan unit rawat jalan RSI Siti Khadijah pada kelima dimensi yaitu Servqual dikatakan rendah karena belum memenuhi ekspektasi pasien (Usama, 2008). Untuk indikator kepuasan pasien rawat inap diperoleh data akhir Agustus 2017 bahwa tercatat 78\% tingkat kepuasan pasien di RSI Siti Khadijah menunjukkan belum mencapai target yang telah ditetapkan yaitu $\geq 90 \%$ (RSI Siti Khadijah, 2017).

Dengan indeks kepuasan tersebut diatas dikhawatirkan adanya penurunan kualitas pelayanan kesehatan yang diberikan oleh RSI Siti Khadijah Palembang kepada pasien, sedangkan salah satu tujuan program Jaminan Kesehatan Nasional (JKN) ialah memberikan hak yang sama untuk semua peserta seperti pelayanan yang bermutu dalam bidang kesehatan. Dengan demikian apabila pelayanan yang diberikan kepada pasien tidak sesuai maka pasien tidak puas dan artinya tujuan dari program Jaminan Kesehatan Nasional belum tercapai. Berdasarkan data BPJS
Kesehatan per November 2017 RSI Siti Khadijah Palembang memfasilitasi pasien peserta BPJS Kesehatan yang tercatat sebanyak 50.894 kunjungan dan merupakan rumah sakit kelas B yang memiliki kunjungan pasien BPJS tertinggi. Kunjungan tersebut mencakup kunjungan Rawat Jalan Tingkat Lanjut (RJTL) sebesar 43.718 dan Rawat Inap sebesar 7.176 yang dilihat dari catatan akhir pendataan November 2017 (BPJS Kesehatan, 2017).

\section{METODE PENELITIAN}

Desain pada penelitian ini cross sectional dengan metode kuantitatif. Populasi pada penelitian ini seluruh pasien peserta Jaminan Kesehatan Nasional (JKN) yang berkunjung dan berobat di Rumah Sakit Islam Siti Khadijah Palembang Juli 2018. Sampel pada penelitian ini yaitu pasien peserta Jaminan Kesehatan Nasional (JKN) yang mendapatkan pelayanan rawat inap di Rumah Sakit Islam Siti Khadijah Palembang Juli 2018 sebanyak 73 sampel yang dipilih secara proportional sampling. Penelitian ini menggunakan data primer dan data sekunder berupa data peserta jaminan kesehatan nasional di Kota Palembang yang didapat dari BPJS Kesehatan Kota Palembang. Analisis data pada penelitian ini menggunakan software statistik dengan uji analisis univariat dan bivariat menggunakan chi-square. Variabel dependen penelitian ini adalah kepuasan pasien rawat inap peserta jaminan kesehatan nasional di Rumah Sakit Islam Siti Khadijah Palembang dengan variabel independen penelitian ini adalah tangible, reliability, responsiveness, assurance dan empathy. 


\section{HASIL DAN PEMBAHASAN}

\section{Analisis Univariat}

Analisis univariat dalam penelitian ini terdiri dari distribusi kepuasan pasien rawat inap RSI Siti Khadijah Palembang, karakteristik responden, dan kualitas pelayanan kesehatan. Adapun hasil analisis univariat secara rinci akan ditampilkan pada Tabel 1 berikut ini:

Tabel 1. Distribusi frekuensi karakteristik pasien rawat inap peserta jaminan kesehatan nasional di Rumah Sakit Islam Siti Khadijah Palembang

\begin{tabular}{|c|c|c|}
\hline \multirow{2}{*}{ Variabel } & \multicolumn{2}{|c|}{ Total Responden } \\
\hline & $\mathbf{n}$ & $\%$ \\
\hline \multicolumn{3}{|l|}{ Variabel Dependen } \\
\hline \multicolumn{3}{|l|}{ Kepuasan Pasien } \\
\hline Puas & 40 & 54,8 \\
\hline Tidak Puas & 33 & 47,2 \\
\hline \multicolumn{3}{|c|}{ Variabel Independen } \\
\hline \multicolumn{3}{|l|}{ Jenis Kelamin } \\
\hline Perempuan & 34 & 46,6 \\
\hline Laki-laki & 39 & 53,4 \\
\hline \multicolumn{3}{|l|}{ Usia } \\
\hline $17-25$ & 16 & 21,9 \\
\hline $26-35$ & 3 & 4,1 \\
\hline $36-45$ & 17 & 23,3 \\
\hline$>45$ & 37 & 50,7 \\
\hline \multicolumn{3}{|l|}{ Pendidikan } \\
\hline Tidak Sekolah & 2 & 2,7 \\
\hline SD & 21 & 28,8 \\
\hline SMP & 8 & 11 \\
\hline SMA & 31 & 42,5 \\
\hline PT & 2 & 2,7 \\
\hline Diploma & 9 & 12,3 \\
\hline \multicolumn{3}{|l|}{ Pekerjaan } \\
\hline Tidak Bekerja & 15 & 20,5 \\
\hline Petani & 7 & 9,6 \\
\hline Buruh & 5 & 6,8 \\
\hline Wiraswasta & 8 & 11 \\
\hline Pelajar/Mahasiswa & 7 & 9,6 \\
\hline PNS/TNI/POLRI & 6 & 8,2 \\
\hline IRT & 14 & 19,2 \\
\hline Lain-lain & 11 & 15,1 \\
\hline \multicolumn{3}{|l|}{ Status Kepesertaan } \\
\hline PBI & 31 & 42,5 \\
\hline Non-PBI & 42 & 57,5 \\
\hline \multicolumn{3}{|l|}{ Asal Rujukan } \\
\hline Puskesmas & 21 & 28,8 \\
\hline Dokter & 8 & 11 \\
\hline Poliklinik RS & 6 & 8,2 \\
\hline UGD RS & 37 & 50,7 \\
\hline Lain-lain & 1 & 1,4 \\
\hline \multicolumn{3}{|l|}{ Lama Perawatan } \\
\hline$\leq 4$ hari & 55 & 75,3 \\
\hline$\geq 5$ hari & 18 & 24,7 \\
\hline
\end{tabular}

Tabel 2. Distribusi frekuensi karakteristik pasien rawat inap peserta jaminan kesehatan nasional di Rumah Sakit Islam Siti Khadijah Palembang

\begin{tabular}{lcc}
\hline \multirow{2}{*}{ Variabel } & \multicolumn{2}{c}{ Total Responden } \\
\cline { 2 - 3 } & n & \% \\
\hline $\begin{array}{l}\text { Pengalaman Perawatan } \\
\text { Sudah Pernah }\end{array}$ & 16 & 21,9 \\
Belum Pernah & 57 & 78,1 \\
Tangible & & \\
Baik & 37 & 50,7 \\
Buruk & 36 & 49,3 \\
Reliability & & \\
Baik & 40 & 54,8 \\
Buruk & 33 & 45,2 \\
Responsiveness & & \\
Baik & 39 & 53,4 \\
Buruk & 34 & 46,6 \\
Assurance & & \\
Baik & 40 & 54,8 \\
Buruk & 33 & 45,2 \\
Empathy & & \\
Baik & 38 & 52,1 \\
Buruk & 35 & 47,9 \\
\hline
\end{tabular}

Berdasarkan Tabel 1, responden yang puas dengan pelayanan kesehatan sebesar 54,8\%. Responden laki-laki lebih banyak dibandingkan responden perempuan, dengan persentase responden laki-laki sebanyak 53,4\%. Mayoritas responden berusia $>45$ tahun dengan persentase $50,7 \%$. Dengan mayoritas tingkat pendidikan pasien yaitu lulusan SMA Sederajat (42,5\%). Dilihat dari status pekerjaan responden yang dominan kebanyakan pasien yang sudah tidak bekerja yaitu dengan presentase $20,5 \%$. Mayoritas status kepesertaan pasien yaitu pasien Non-PBI dengan persentase 57,5\%. Pasien rawat inap dominan dengan status kepesertaan baru atau belum pernah dirawat di RSI Siti Khadijah dengan persentase $78,1 \%$ dan untuk lama perawatannya pasien mayoritas $\leq 4$ hari dengan persentase $75,3 \%$. Sedangkan kualitas pelayanan yang didapatkan pasien keseluruhan menyatakan bahwa pelayanan baik yaitu tangible dengan persentase $50,7 \%$, reliability dengan persentase $54,8 \%$, responsiveness dengan persentase $53,4 \%$, assurance dengan persentase 
$54,8 \%$, dan empathy dengan persentase $52,1 \%$.

\section{Analisis Bivariat}

Analisis bivariat dilakukan untuk mengetahui hubungan antara variabel independen yaitu mutu pelayanan kesehatan (tangible, reliability, responsiveness, assurance dan empathy) dengan variabel dependen yaitu kepuasan pasien rawat inap peserta jaminan kesehatan nasional di RSI Siti Khadijah Palembang yang dijelaskan dalam Tabel 3 berikut:

Tabel 3. Hubungan Mutu Pelayanan Kesehatan (Tangible, Reliability, Responsiveness, Assurance Dan Empathy) Dengan Kepuasan Pasien Rawat Inap Peserta Jaminan Kesehatan Nasional (JKN) Di RSI Siti Khadijah Palembang

\begin{tabular}{|c|c|c|c|c|c|c|c|c|}
\hline \multirow{3}{*}{ Variabel } & \multicolumn{4}{|c|}{ Kepuasan Pasien } & \multirow{2}{*}{\multicolumn{2}{|c|}{ Total }} & \multirow{3}{*}{ P-value } & \multirow{3}{*}{$\begin{array}{c}\text { PR } \\
(95 \% \mathrm{CI})\end{array}$} \\
\hline & \multicolumn{2}{|c|}{ Puas } & \multicolumn{2}{|c|}{ Tidak Puas } & & & & \\
\hline & $\mathbf{n}$ & $\%$ & $\mathbf{n}$ & $\%$ & $\mathbf{n}$ & $\%$ & & \\
\hline \multicolumn{9}{|l|}{ Tangible } \\
\hline Baik & 27 & 73 & 10 & 27,0 & 37 & 100 & \multirow{2}{*}{0,003} & 2.021 \\
\hline Buruk & 13 & 36,1 & 23 & 63,9 & 36 & 100 & & $(1.255-3.255)$ \\
\hline
\end{tabular}

Tabel 4. Hubungan Mutu Pelayanan Kesehatan (Tangible, Reliability, Responsiveness, Assurance Dan Empathy) Dengan Kepuasan Pasien Rawat Inap Peserta Jaminan Kesehatan Nasional (JKN) Di RSI Siti Khadijah Palembang

\begin{tabular}{|c|c|c|c|c|c|c|c|c|}
\hline \multirow{3}{*}{ Variabel } & \multicolumn{4}{|c|}{ Kepuasan Pasien } & \multirow{2}{*}{\multicolumn{2}{|c|}{ Total }} & \multirow{3}{*}{ P-value } & \multirow{3}{*}{$\begin{array}{c}\text { PR } \\
(95 \% \text { CI })\end{array}$} \\
\hline & \multicolumn{2}{|c|}{ Puas } & \multicolumn{2}{|c|}{ Tidak Puas } & & & & \\
\hline & n & $\%$ & $\mathbf{n}$ & $\%$ & $\mathbf{n}$ & $\%$ & & \\
\hline \multicolumn{9}{|l|}{ Realibility } \\
\hline Baik & 31 & 77,5 & 9 & 22,5 & 40 & 100 & \multirow{2}{*}{0,000} & 2.842 \\
\hline Buruk & 9 & 27,3 & 24 & 72,7 & 33 & 100 & & $(1.588-5.084)$ \\
\hline \multicolumn{9}{|c|}{ Responsiveness } \\
\hline Baik & 32 & 82,1 & 7 & 17,9 & 39 & 100 & \multirow{2}{*}{0,000} & 3.487 \\
\hline Buruk & 8 & 23,5 & 26 & 76,5 & 34 & 100 & & $(1.869-6.505)$ \\
\hline \multicolumn{9}{|l|}{ Assurance } \\
\hline Baik & 33 & 82,5 & 7 & 17,5 & 40 & 100 & \multirow{2}{*}{0,000} & 3.889 \\
\hline Buruk & 7 & 21,2 & 26 & 78,8 & 33 & 100 & & $(1.984-7.622)$ \\
\hline \multicolumn{9}{|l|}{ Empathy } \\
\hline Baik & 33 & 86,8 & 5 & 13,2 & 38 & 100 & \multirow{2}{*}{0,000} & 4.342 \\
\hline Buruk & 7 & 20,0 & 28 & 80,0 & 35 & 100 & & $(2.213-8.520)$ \\
\hline
\end{tabular}

Berdasarkan Tabel 4, menunjukkan bahwa ada hubungan variabel tangible ( $p$ value $=0,003)$, realibility $(p$-value $=$ $0,000)$, responsiveness $(p$-value $=0,000)$, assurance ( $p$-value $=0,000)$, dan empathy $(p$-value $=0,000)$ dengan kepuasan pasien rawat inap peserta jaminan kesehatan nasional.

Hubungan Dimensi Bukti Fisik (Tangiabile) Dengan Kepuasan Pasien Rawat Inap Peserta Jaminan Kesehatan Nasional (JKN)

Hasil penelitian menunjukkan bahwa tingkat kepuasan pasien rawat inap peserta JKN di RSI Siti Khadijah
Palembang berdasarkan bukti fisik (tangible) yang baik dan pasien merasa puas sebesar $73 \%$. Berdasarkan uji chisquare yang dilakukan terdapat hubungan yang signifikan antara bukti fisik (tangible) dengan kepuasan pasien dengan nilai $p$ value sebesar $0,003<0,05$ ) nilai PR sebesar 2,021 dengan nilai rentang CI 95\% CI $(1,255-3,255)$.

Sejalan dengan hasil penelitian menyebutkan terdapat hubungan antara tangible dengan kepuasan pasien rawat inap dilihat dari nilai $p$-value yaitu 0,001 , menurutnya pada umumnya seseorang akan memandang suatu potensi rumah sakit awalnya dari kondisi fisik, dengan 
kondisi yang bersih, rapi, dan teratur orang akan menduga bahwa rumah sakit tersebut melaksanakan fungsinya dengan baik (Pangerapan dkk., 2018). Menurut Suryati (2006) dalam Manengkei (2016) menyatakan bahwa aspek bukti fisik menjadi penting sebagai ukuran terhadap pelayanan yang diberikan oleh pelayanan kesehatan terhadap pasien.

Dalam penelitian ini cenderung pasien sangat puas dengan penampilan dokter dan perawat serta keadaan lingkungan ruang perawatan yang tampak rapi dan bersih sehingga penilaian pasien mengenai kondisi fisik rumah sakit sangat baik. Namun disisi lain terdapat ketidaknyamanan pasien dan keluarga mengenai fasilitas pelayanan berupa kondisi WC yang tidak begitu baik, karena saluran air yang tersumbat sehingga menyebabkan lantai WC tergenang air dan kotor.

\section{Hubungan Dimensi Kehandalan (Realibility) Dengan Kepuasan Pasien Rawat Inap Peserta Jaminan Kesehatan Nasional (JKN)}

Berdasarkan tabulasi silang yang dilakukan antara kehandalan dengan kepuasan pasien, diperoleh data bahwa dari bahwa dari 40 responden $(100 \%)$ yang menyatakan baik terhadap kehandalan (reliability) terdapat 31 responden $(77,5 \%)$ merasa puas dan 9 responden $(22,5 \%)$ merasa tidak puas. Sedangkan dari 33 responden (100\%) yang menyatakan buruk terhadap bukti kehandalan (reliability) terdapat 9 responden $(27,3 \%)$ yang merasa puas dan 24 responden $(72,7 \%)$ merasa tidak puas. Hasil uji statistic chi-square diperoleh nilai $p=0.000<0.05$ dengan nilai $\mathrm{PR}$ sebesar 2,842 dengan nilai rentang CI 95\% CI (1,588-5,084) artinya terdapat hubungan yang signifikan antara realibility dengan kepuasan pasien rawat inap peserta jaminan kesehatan di RSI Siti Khadijah Palembang.
Sejalan dengan hasil penelitian yang menyebutkan ada hubungan antara realibility dengan kepuasan pasien rawat inap dilihat dari p-value yaitu 0,006 (Hatibie, 2015). Penelitian lain yang mengatakan terdapat hubungan ang signifikan antara realibility dengan kepuasan pasien rawat inap dengan $p$ value aitu 0,007 (Hastuti dkk., 2017).

Sebuah rumah sakit dikatakan handal kalau proses penerimaan pasien dilakukan dengan cepat dan prosedur pengadministrasian yang tidak berbelitbelit, tindakan yang cepat dan tepat terhadap pemeriksaan secara cepat dan tepat (Supranto, 2011). Pada dasarnya pasien rawat inap di RSI Siti Khadijah Palembang mengakui bahwa pelayanannya mulai dari prosedur dan kecepatan penerimaan pasien sangatlah baik, sehingga pasien merasa puas dengan pelayanan tersebut dan beberapa pasien merasakan kurangnya ketepatan atau estimasi waktu yang diberikan kepada pasien sebelum mendapatkan kamar rawat inap.

\section{Hubungan Dimensi Ketanggapan (Responsiveness) Dengan Kepuasan Pasien Rawat Inap Peserta Jaminan Kesehatan Nasional (JKN)}

Setelah melakukan uji statistik chisquare dapat disimpulkan bahwa terdapat hubungan yang signifikan antara ketanggapan dengan kepuasan pasien rawat inap peserta Jaminan Kesehatan Nasional (JKN) di RSI Siti Khadijah Palembang dengan nilai $\mathrm{p}$ value $(0,000)<$ $(0,05)$ dengan nilai PR sebesar 3,487 dimana nilai rentang CI 95\% CI $(1,869$ 6,505). Beberapa komponen penilaian pada variabel ini yaitu, dokter selalu menanyakan keluhan pasien, dokter memberikan kesempatan bertanya kepada pasien, ketepatan dan kecepatan pelayanan yang diberikan kepada pasien, dan perawat memperhatikan kebutuhan dan keluhan pasien. 
Ketanggapan menunjukan adanya keinginan untuk membantu konsumen dan memberikan pelayanan dengan cepat dan tepat (Mukti, 2007). Rumah sakit dikatakan memiliki daya tanggap apabila petugas selalu siap sedia untuk membantu pasien pemberian yang jelas kepada pasien, dan cepat tanggap terhadap keluhan pasien (Sondari, 2017).

Pasien rawat inap di RSI Siti Khadijah Palembang sangat puas dengan ketanggapan petugas kesehatan yang selalu mendengarkan dan menerima keluhan pasien dengan baik.

\section{Hubungan Dimensi Jaminan (Assurance) Dengan Kepuasan Pasien Rawat Inap Peserta Jaminan Kesehatan Nasional (JKN)}

Hasil analisis uji statistic chi-square diperoleh nilai $p=0.000<0.05$ maka $H_{0}$ ditolak dan $H_{\alpha}$ diterima, menunjukkan bahwa ada hubungan yang signifikan antara jaminan (assurance) dengan tingkat kepuasan pasien pada pasien rawat inap peserta Jaminan Kesehatan Nasional (JKN) di RSI Siti Khadijah Palembang, hasil nilai PR sebesar 3,889 dengan nilai rentang CI 95\%CI (1,984-7,622). Menurut Parasuraman dkk. (1988) dalam Triwardani (2017), Assurance merupakan kompetensi yang dimiliki oleh petugas pelayanan yang membuat rasa aman dan bebas resiko atau bahaya, kepastian yang mencakup pengetahuan yang luas, sikap dan perilaku yang sopan terhadap pasien sehingga menumbuhkan kepercayaan dan keyakinan pasien.

Sejalan dengan penelitian sebelumnya yang menyatakan bahwa ada hubungan yang signifikan antara assurance dengan kepuasan pasien, menurutnya jaminan yang baik akan meningkatkan kepuasan pasien terhadap pelayanan rumah sakit, sehingga membuat pasien cenderung percaya dengan pelayanan yang dilakukan oleh rumah sakit (Ariani, 2009). Winardi dkk. (2014) juga menjelaskan bahwa ada hubungan yang signifikan antara jaminan dengan kepuasan pasien. Sedangkan penelitian lain menjelaskan tidak ada hubungan antara assurance dengan kepuasan pasien dimana nilai $p=0,195>0,05$ (Pangerapan dkk., 2018).

Berdasarkan hasil penelitian menunjukkan sebesar $(82,5 \%)$ pasien merasa puas dengan pelayanan jaminan (Assurance) yang ada di RSI Siti Khadijah Palembang. Kepuasan yang dirasakan pasien lebih dominan pada penampilan sikap dokter dan perawat yang ramah terhadap pasien dan keluarga pasien dan dokter datang sesuai dengan jadwalnya. Pada jaminan (assurance) yang baik dan pasien rawat inap peserta JKN merasa tidak puas sebesar $(17,5 \%)$, hal ini disebabkan oleh ada sebagian perawat yang cuek dan judes terhadap pasien sehingga pasien merasa tidak nyaman dengan hal tersebut.

\section{Hubungan Dimensi Perhatian (Empathy) Dengan Kepuasan Pasien Rawat Inap Peserta Jaminan Kesehatan Nasional (JKN)}

Uji statistik chi-square didapatkan bahwa nilai $p=0.000<0.05$ maka $H_{0}$ ditolak dan $H_{a}$ diterima, menunjukkan bahwa terdapat hubungan diantara kedua variabel perhatian (empathy) dengan kepuasan pasien, dimana hasil nilai PR sebesar 4,342 dengan nilai rentang CI 95\% CI (2,213-8,520). Penelitian ini terdiri atas lima komponen penilaian yaitu keterampilan dokter dan perawat dalam menenangkan rasa cemas pasien, dokter atau perawat meluangkan waktu khusus untuk berkonsultasi, perawat selalu mengingatkan keamanan pada pasien dan keluarga, waktu untuk berkonsultasi terpenuhi, dan keterampilan petugas dalam mengibur dan mendoakan kesembuhan pasien. 
Berdasarkan hasil wawancara yang dilakukan peneliti terhadap pasien, mereka puas dengan pelayanan atau perhatian yang diberikan oleh dokter dan perawat meskipun tidak semua petugas terlihat akrab, meskipun terkadang waktu yang terjadwal hanya sedikit. Untuk lebih meningkatkan kualitas pelayanan sebaiknya pasien atau keluarga pasien diberikan waktu untuk berkonsultasi agar mereka memahami betul tentang penyakit yang diderita, karena dari beberapa pasien yang diwawancarai mengatakan bahwa mereka sulit untuk berkonsultasi dikarenakan dokter sudah pergi.

Hubungan perhatian dengan kepuasan pasien ialah perhatian mempunyai pengaruh positif dan signifikan terhadap kepuasan pasien (Muninjaya, 2011). Penelitian lain yang sejalan dengan penelitian ini juga menyatakan ada hubungan yang signifikan antara empathy dengan kepuasan pasien dilihat dari nilai $p$-value 0,000 (Hatibie, 2015).

\section{KESIMPULAN}

Terdapat hubungan antara variabel tangible, reliability, responsiveness, assurance dan empathy dengan kepuasan pasien rawat inap peserta jaminan kesehatan nasional di RSI Siti Khadijah Palembang.

\section{SARAN}

Saran dari penelitian ini adalah sebagai berikut:

Bagi RSI Siti Khdijah Palembang :
1. Disarankan agar RSI Siti Khadijah Palembang dapat melakukan perbaikan, peningkatan, dan pengembangan sarana fisik seperti membersihkan ruang perawatan dan lingkungan disekitarnya agar tertata lebih rapi dan bersih, memperbaiki saluran pembuangan air agar tidak lagi terjadi banjir dan diharapkan dapat memberikan kenyamanan terhadap pasien dan keluarga yang menjaga.

2. Disarankan agar petugas memberikan kejelasan waktu tunggu terhadap pasien saat menunggu kamar rawat inap.

3. Disarankan agar RSI Siti Khadijah Palembang untuk memberikan pelatihan-pelatihan keterampilan kepada petugas kesehatan dalam berkomunikasi dengan baik kepada pasien agar informasi yang diberikan dapat diterima dan mudah dimengerti pasien dan keluarga pasien, serta memberikan keadilan pada setiap pelanggan dan memahami kebutuhan pelanggan.

4. Disarankan agar dokter di RSI Siti Khadijah Palembang bagian rawat inap memberikan waktu untuk berkonsultasi khusus dengan pasien dan memperpanjang waktu visitasi.

Bagi Peneliti Selanjutnya

Untuk penelitian selanjutnya variabel yang digunakan sebaiknya dikembangkan lagi dengan memperbanyak bahasan mengenai faktorfaktor kepuasan pasien dan penambahan penggunaan metode kualitatif untuk mendapatkan informasi yang lebih dalam.

\section{DAFTAR PUSTAKA}

Ariani, D. Wahyu. (2009). Manajemen Operasi Jasa. Graha Ilmu, Yogyakarta. BPJS. (2017). INFO BPJS Kesehatan Kota Palembang. BPJS Kesehatan. 
Hardi, J. (2010). Analisis Tingkat Kepuasan Pasien Umum dan Pasien Jamksesmas Terhadap Mutu Pelayanan Rawat Inap di RSUD Pasaman Barat Tahun 2010. Tesis. Program Pascasarjana Universitas Andalas.

Hastuti, S.K.W. (2017). Hubungan Mutu Pelayanan dengan Kepuasan Pasien Pesera BPJS di Rumah Sakit Umum Daerah Yogyakarta. Jurnal Fakultas Kesehatan Masyarakat. Volume 11. No 2.

Hatibie, T. W. J., Rattu, A.J.M. \& Pasiak, T. (2015). Analisis Faktor-Faktor yang Berhubungan dengan Kepuasan Pasien di Instalasi Rawat Jalan Bedah RSUP Prof. Dr. R. D. Kandou Manado. Jurnal JIKMU. Volume 5. No. 2.

Ikegami, N. (2014). Universal Health Coverage for Inclusive and Sustainable Development. World Bank Group, Japan.

Mukti, Ali Ghufron. (2007). StrategiTerkini Peningkatan Mutu Pelayanan Kesehatan : Konsep Implementasi. PT. Karya Husada Mukti, Yogyakarta.

Muninjaya, A. A. G. (2011). Manajemen Kesehatan. EGC, Jakarta.

Pangerapan, D. T., Palandeng, O. E. L. I. \& Rattu, A. J. M. (2018). Hubungan Antara Mutu Pelayanan Dengan Kepuasan Pasien Di Poliklinik Penyakit Dalam Rumah Sakit Umum GMIM Pancaran Kasih Manado. Jurnal Kedokteran Klinik (Jkk). Volume 2. No 1.

Soendari, A. \& Bambang, B.R. (2017). Tingkat Kepuasan Pasien Rawat Jalan Peserta Jaminan Kesehatan Nasional (JKN). HIGEIA: Journal Of Public Health Research And Development.

Supranto, J. (2011). Pengukuran Tingkat Kepuasan Pelanggan, Rineka Cipta, Jakarta.

Triwardani, Y. (2017). Faktor-Faktor yang Berhubungan dengan Kepuasan Pasien BPJS Pada Pelayanan di Puskesmas Pamulang. Skripsi. Universitas Islam Negeri (UIN) Syarif Hidayatullah Jakarta. Jakarta Selatan.

Usama, S. (2008). Analisis Kualitas Pelayanan Instalasi Rawat Jalan di Rumah Sakit Islam Siti Khadijah Palembang dengan Menggunakan Metode Servqual. Skripsi. Universitas Indonesia, Depok.

Wardani, A. E. (2017). Tingkat Kepuasan Pasien Rawat Inap Peserta Jaminan Kesehatan Nasional (JKN) di Rumah Sakit Umum Daerah La Temmamala Kabupaten Soppeng. Skripsi. UIN Alauddin Makassar, Makassar.

Yandrizal, Rifa'i, \& Selpa, P.U. (2015). Analisis Kemampuan Dan Kemauan Membayar Iuran Terhadap Pencapaian UHC JKN Di Kota Bengkulu. JKMA : Fakultas Kesehatan Masyarakat Universitas Andalas. 